\title{
Prolongamento da vida pós-colheita de bananas-maçã submetidas ao 1-metilciclopropeno (1-MCP) - qualidade sensorial e física
}

\author{
Extension of postharvest life of 'Apple' banana subjected to \\ 1-methylcyclopropene (1-MCP) - sensory and physical quality
}

\author{
Ana Carla Marques PINHEIRO ${ }^{1 \star}$, Eduardo Valério de Barros VILAS BOAS ${ }^{1}$, Helena Maria André BOLINI ${ }^{2}$
}

\begin{abstract}
Resumo
Objetivou-se avaliar o efeito do 1-metilciclopropeno (1-MCP) sobre a qualidade e extensão da vida pós-colheita de bananas-maçã. Frutas no grau 2 de coloração da casca foram tratadas com 50 nL.L $\mathrm{L}^{-1}$ de 1-MCP durante 0 (controle), 6, 9, 12 e 24 horas. Posteriormente, foram armazenadas sob condição ambiente: $22 \pm 2{ }^{\circ} \mathrm{C} 85 \pm 5 \%$ UR. Avaliaram-se as características sensoriais: aparência dos frutos no grau 4 (frutos mais verdes que amarelos) e grau 7 (frutos amarelos com pontuações marrons) de coloração da casca; descasque, aroma, sabor, firmeza da polpa e aspecto global nos frutos no grau 7, utilizando-se um teste de aceitabilidade através de escala hedônica de 9 pontos; e ainda a intenção de compra nos frutos nos graus 4 e 7, através de escala de 5 pontos. Avaliou-se também, visualmente, a extensão da vida pós-colheita, e, instrumentalmente, a coloração da casca e firmeza da polpa. Conclui-se que a aplicação de $50 \mathrm{~nL} . \mathrm{L}^{-1}$ por um período de 12 horas é a mais adequada, pois promove extensão na vida pós-colheita de bananas-maçã, armazenadas em temperatura ambiente, em aproximadamente 11 dias, sem alterar a qualidade sensorial, a intenção de compra, coloração da casca e firmeza dos frutos quando maduros, comparados ao controle.
\end{abstract}

Palavras-chave: análise sensorial; Musa sp.; coloração; firmeza; vida útil.

\begin{abstract}
The objective of this work was to evaluate the effect of 1-methylcyclopropene (1-MCP) on the quality and extension of postharvest life of 'Apple' banana. The fruit, at degree 2 of peel color was treated with $50 \mathrm{~nL} . \mathrm{L}^{-1}$ of 1-MCP for 0 (control), 6, 9, 12 and 24 hours. Next, It was stored at room temperature: $22 \pm 2{ }^{\circ} \mathrm{C} 85 \pm 5$ per cent RH. The following sensory characteristics were evaluated: appearance of the fruit at degree 4 (greener than yellow) and degree 7 (yellow with brown spots) of peel color; peeling, aroma, flavor, firmness of pulp and global aspect of the fruit at degree 7, using a test of acceptability using the 9-point hedonic scale and also the intention of buying the fruit at degrees 4 and 7 , using a 5-point scale. Also evaluated visually was the extension of postharvest life and instrumentally the peel color and pulp firmness. It was concluded that the application of $50 \mathrm{~nL} . \mathrm{L}^{-1}$ for a period of 12 hours is the most suitable, because it promotes the extension of the postharvest life of 'Apple' bananas, stored at room temperature for approximately 11 days, without affecting the sensory quality, buying intention, peel color and firmness of fruit when ripe, in comparison to control.

Keywords: sensory analysis; Musa sp.; color; firmness; shelf life.
\end{abstract}

\section{Introdução}

A banana, muito apreciada no Brasil e no mundo, é a quarta cultura agrícola mais importante do planeta, atrás apenas do arroz, do trigo e do milho (EMBRAPA, 2006). Além disso, tem ainda uma enorme importância social, pois é uma fonte de energia, minerais e vitaminas de baixo custo. O Brasil é o segundo maior produtor mundial de banana, responsável por cerca de 9,5\% da produção (EMBRAPA, 2006). De acordo com Brasil (2007a), o País produziu 6.997.000 toneladas de banana em 2005, exportando 212.176 toneladas, ou seja, $3,03 \%$ de toda a produção. Esta pequena participação no mercado externo é devida, principalmente, aos altos índices de perdas e alto consumo interno da fruta (CENARGEN, 2006). Dentre as cultivares exploradas, a banana-maçã caracterizase por apresentar qualidades sensoriais agradáveis, sendo, talvez, a mais saborosa de todas as variedades para consumo ao natural. Além disso, seu cultivo é de alta rentabilidade econômica (AGRIANUAL, 2007). A banana é um fruto climatérico altamente perecível, apresentando uma elevação na taxa respiratória e produção de etileno que desencadeia o amadurecimento, dificultando a comercialização do produto em locais mais distantes e acarretando altos índices de perdas. O etileno é um composto orgânico volátil que difunde dentro e fora das células, estimulando as modificações relativas ao amadurecimento como coloração, aroma, sabor e textura da banana. Em condições normais, o etileno liga-se a moléculas receptoras, provavelmente proteínas de membrana, de onde surgem respostas associadas ao amadurecimento (GOLDING et al., 1998). O 1-metilciclopropeno (1-MCP) é um produto que atua inibindo temporariamente esta ação do etileno e, consequentemente, o amadurecimento dos frutos. De acordo

Recebido para publicação em 27/2/2008

Aceito para publicação em 5/1/2009 (003276)

${ }^{1}$ Departamento de Ciência dos Alimentos - DCA, Universidade Federal de Lavras - UFLA, CP 3037, Lavras - MG, Brasil, E-mail: anacarlamp@ufla.br; evbvboas@ufla.br

${ }^{2}$ Departamento de Alimentos e Nutrição - DEPAN, Faculdade de Engenharia de Alimentos - FEA, Universidade de Campinas - UNICAMP, CP 6121, Campinas - SP, Brasil, hellini@fea.unicamp.br

${ }^{*}$ A quem a correspondência deve ser enviada 
com a portaria $\mathrm{n}^{\circ} 354$ de 11 de agosto de 2006 da ANVISA (BRASIL, 2006), o 1-MCP foi liberado para utilização no Brasil em diferentes plantas ornamentais e frutos, dentre os quais se inclui a banana. Este produto tem sido avaliado na extensão da vida pós-colheita e manutenção da qualidade de diversos produtos vegetais (PINHEIRO; VILAS BOAS; MESQUITA, 2005; PINHEIRO et al., 2006; BLANKENSHIP; DOLE, 2003; BOTREL et al., 2002; HARRIS et al., 2000; GOLDING et al., 1998). Entretanto, são poucos os estudos que avaliam o impacto da utilização do 1-MCP na qualidade sensorial de vegetais comestíveis, devido principalmente ao recente registro do produto e liberação para uso comercial restrita a poucas frutas e hortaliças (WATKINS, 2006). Pinheiro et al. (2006) relataram que a aplicação de 50, 100, 150 e 200 ๆL.L $L^{-1}$ de 1-MCP, durante 12 horas, ocasionou amarelecimento desuniforme durante o amadurecimento de banana cv. Maçã e as três últimas doses, tonalidade avermelhada na casca, comprometendo a aparência do fruto. Golding et al. (1998), Jiang, Joyce e Macnish (1999) e Harris et al. (2000) também relataram a ocorrência de amarelecimento desuniforme na casca de diferentes cultivares de bananas submetidas ao 1-MCP. A qualidade dos produtos alimentícios sejam eles de origem vegetal ou animal, processados ou in natura, está associada aos aspectos sensoriais, nutritivos e de segurança. O aspecto sensorial é avaliado através da aparência, aroma, sabor e textura, sendo a aparência o primeiro atributo a ser observado pelo consumidor no momento da compra e os demais avaliados em sequência. Desta forma é extremamente importante preservar a qualidade sensorial dos produtos para a garantia do sucesso na comercialização. Em função da carência de estudos na avaliação sensorial de produtos vegetais submetidos ao tratamento com 1-MCP, objetivou-se

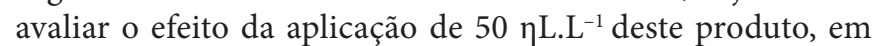
diferentes tempos, na qualidade sensorial, sob o ponto de vista do consumidor, juntamente com análises instrumentais e extensão da vida útil de bananas da cv. Maçã.

\section{Material e métodos}

\subsection{Material}

Bananas da cv. Maçã, cultivadas utilizando-se métodos culturais tradicionais para a cultura, foram adquiridas em uma pequena propriedade rural próxima ao município de Lavras-MG, no estádio 2 de coloração da casca (frutos maturos, completamente verdes) e com aproximadamente $3 \mathrm{~cm}$ de diâmetro. Os frutos foram, em seguida, transportados sob temperatura ambiente para o Laboratório de Pós-colheita de Frutas e Hortaliças da Universidade Federal de Lavras, onde foram tratados utilizando-se uma dosagem única de 50 ๆL.L - $^{-1}$ 1-metilciclopropeno (1-MCP), na formulação pó, com $0,14 \%$ de ingrediente ativo, variando-se o tempo de aplicação. A aplicação foi realizada em caixas de isopor com volume de $100 \mathrm{~L}$, hermeticamente fechadas, nas quais os frutos permaneceram por $0,6,9,12$ e 24 horas em contato com o produto. Após a aplicação, foram removidos das caixas e armazenados sob condição ambiente: $22 \pm 2{ }^{\circ} \mathrm{C}$ e $80 \pm 5 \%$ UR.

\subsection{Métodos}

\section{Análise sensorial}

A avaliação da aceitação da aparência dos frutos e a intenção de compra (IC) foram realizadas no grau 4 de coloração da casca (frutos mais verdes que amarelos) e, posteriormente, no grau 7 (frutos completamente amarelos com pontuações marrons/ aptos ao consumo), utilizando-se cabine comum aos provadores, iluminada com luz fluorescente branca. A aceitação em relação ao descasque, aroma de banana, sabor de banana, firmeza da polpa e aspecto global, foram avaliados individualmente somente em frutos no grau 7 , em cabines também iluminadas com lâmpadas fluorescentes brancas. O teste de aceitação com 40 consumidores de banana cv. Maçã foi realizado utilizandose escala hedônica estruturada mista de 9 pontos ( 9 - gostei extremamente a 1 - desgostei extremamente) (MEILGAARD; CIVILLE; CARR, 1999) e escala de 5 pontos para avaliar a intenção de compra (5-certamente compraria a 1 - certamente não compraria). Cada uma das amostras, composta por uma banana madura (apta ao consumo), sem o pedúnculo, foi servida na forma monádica em bandejas brancas de isopor identificadas com números aleatórios de três dígitos. Todos os consumidores avaliaram a aceitação em relação a todas as amostras em blocos casualizados completos balanceados, correspondentes aos 5 tempos de aplicação de 1-MCP (0, 6, 9, 12 e 24 h).

\section{Análise da extensão da vida pós-colheita e análises físicas}

Através de análise visual, foi avaliada a extensão da vida pós-colheita, computando-se o número de dias decorridos para ocorrência das primeiras mudanças visíveis de coloração da casca de verde para amarelo e número de dias decorridos para que atingissem o grau 7 (frutos completamente amarelos com manchas marrons/aptos ao consumo).

Foi avaliada também, através de análise instrumental, a coloração da casca, determinada na região equatorial do fruto, utilizando-se Colorímetro marca Minolta, modelo CR 400 sistema CIE Lab, com a determinação das coordenadas $a^{\star}$ e $\mathrm{b}^{*}$, sendo a coordenada $\mathrm{a}^{*}$ relacionada com a intensidade de verde/vermelho e a coordenada $b^{*}$ com a intensidade de azul/ amarelo.

A firmeza da polpa, expressa em Newtons (N), foi avaliada em rodelas sem casca retiradas da região equatorial, utilizandose texturômetro modelo TA.TX2i equipado com sonda de aço inoxidável de $8 \mathrm{~mm}$ de diâmetro (P/6N), que mediu a força de penetração nas rodelas com velocidade de descida de $10 \mathrm{~mm} / \mathrm{s}$ e com distância máxima de introdução de $10 \mathrm{~mm}$.

As análises instrumental e de extensão da vida pós-colheita seguiram um delineamento inteiramente casualizado com 5 tempos de aplicação do produto e dois graus de coloração da casca (graus 4 e 7), com três repetições, sendo a parcela experimental composta por três buquês com 3 a 4 dedos.

\section{Análise estatística}

Os dados foram analisados estatisticamente por análise de variância (ANOVA) e teste de médias de Tukey $(\mathrm{p}<0,05)$, utilizando-se programa estatístico SISVAR versão 4.0 (FERREIRA, 2000). 


\section{Resultados e discussão}

Analisando-se a Tabela 1, podemos notar que a aplicação de $50 \eta \mathrm{L} . \mathrm{L}^{-1}$ de 1-MCP, independentemente do tempo, retardou de forma significativa o início do amadurecimento, baseando-se nas primeiras mudanças de coloração da casca, aumentando, consequentemente, a vida pós-colheita destes frutos (Figura 1). A aplicação de 1-MCP durante 6 e 9 horas retardou o início das primeiras mudanças de coloração da casca dos frutos em aproximadamente 4 e 8 dias, respectivamente, enquanto a aplicação durante 12 e 24 horas retardou em aproximadamente 11 dias, quando comparados ao controle (0 horas).

Tabela 1. Prolongamento da vida pós-colheita de bananas cv. Maçã submetidas a $50 \eta \mathrm{L} . \mathrm{L}^{-1}$ de $1-\mathrm{MCP}$, em diferentes tempos e armazenadas a $25 \pm 3{ }^{\circ} \mathrm{C}$ e $85 \pm 5 \%$ UR.

\begin{tabular}{|c|c|c|}
\hline \multirow{2}{*}{$\begin{array}{c}\text { Tempo de aplicação } \\
\text { de } 50 \eta L^{-1} 1-\mathrm{MCP} \\
\text { (horas) }\end{array}$} & \multicolumn{2}{|c|}{$\mathrm{N}^{\circ}$ dias } \\
\hline & $\begin{array}{c}\text { Primeiras mudanças } \\
\text { de cor da casca }\end{array}$ & Grau 7 \\
\hline 0 (controle) & $4,73^{\mathrm{a}}$ & $10,90^{c}$ \\
\hline 6 & $8,88^{\mathrm{b}}$ & $14,68^{\mathrm{b}}$ \\
\hline 9 & $12,98^{\mathrm{c}}$ & $18,30^{\mathrm{b}}$ \\
\hline 12 & $15,25^{\mathrm{d}}$ & $24,24^{\mathrm{a}}$ \\
\hline 24 & $16,08^{\mathrm{d}}$ & $25,36^{\mathrm{a}}$ \\
\hline
\end{tabular}

Médias seguidas de letras em comum, na coluna, são iguais entre si pelo Teste de Tukey $(\mathrm{p}>0,05)$.

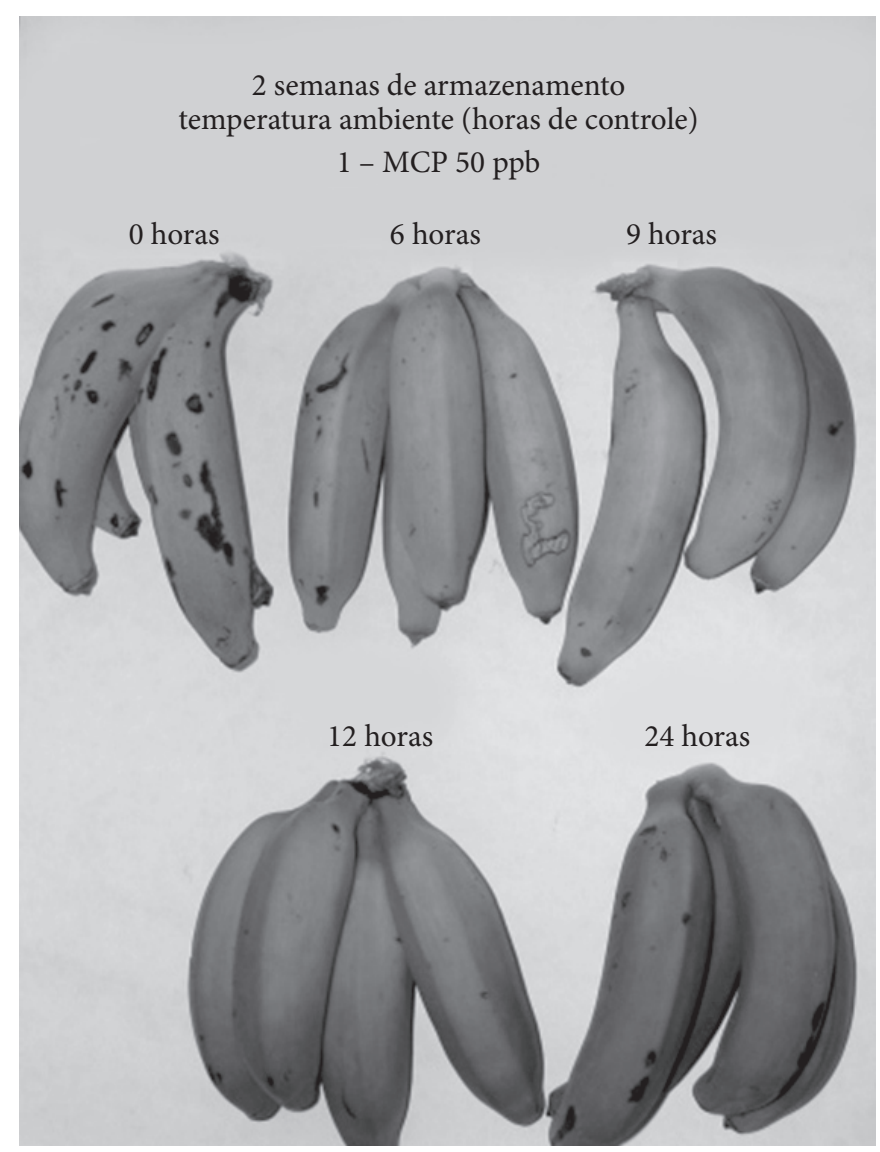

Figura 1. Ilustração do prolongamento da vida pós-colheita de bananas 'Maçã' submetidas a 50 nL.L ${ }^{-1}$ de $1-\mathrm{MCP}$, em diferentes tempos e armazenadas a $22 \pm 2{ }^{\circ} \mathrm{C}$ e $80 \pm 5 \%$ UR.
Trabalhando com bananas da cv. Maçã submetidas a 50, 100, 150 e 200 nL.L ${ }^{-1}$ de 1 -MCP durante 12 horas e armazenadas a $20 \pm 1{ }^{\circ} \mathrm{C}$ e $80 \pm 5 \%$ UR, Pinheiro, Vilas Boas e Mesquita (2005) apresentaram resultados de atraso no início do amadurecimento de aproximadamente 10 dias para as concentrações de 100 , 150 e 200 nL.L $L^{-1}$ e 8 dias para a concentração de 50 nL.L $L^{-1}$ de 1-MCP. Esta diferença de 3 dias a mais na extensão da vida útil entre a aplicação de 50 nL.L $\mathrm{L}^{-1}$ durante 12 horas neste trabalho e a citada por Pinheiro, Vilas Boas e Mesquita (2005) podem ser decorrentes de influência de fatores pré-colheita (condições climáticas, tratos culturais) e ponto de colheita dos frutos.

Avaliando-se a aparência dos frutos no grau 4 de coloração da casca, é possível observar diferença significativa entre os frutos tratados durante 24 horas e aqueles tratados durante 0 (controle) e 6 horas, sendo que os frutos sob os demais tratamentos, 9 e 12 horas, não diferiram dos frutos controle (Tabela 2). Houve diferença estatística $(\mathrm{p}<0,05)$ também na intenção de compra (IC) dos frutos no grau 4, em que os frutos submetidos à aplicação de 1-MCP durante 6 horas apresentaram IC igual ao controle. Os demais tratamentos, entretanto, apresentaram IC inferior ao controle, demonstrando assim diferença na aquisição, e iguais estatisticamente ao tratamento de 6 horas (Tabela 2).

Os frutos submetidos ao 1-MCP apresentaram desverdecimento desuniforme da casca, menos intenso nos frutos sob aplicação durante 6 horas que, com o avanço do amadurecimento, atingiam coloração amarela com extremidades verdes, finalizando o processo de desverdecimento desuniforme. Talvez este fato possa justificar a menor IC dos frutos tratados com 1-MCP durante 9, 12 e 24 horas, já que foram avaliados no grau 4 de coloração da casca (frutos com casca mais verde que amarela) onde o amarelecimento desuniforme era ainda visível.

Analisando-se as características sensoriais das bananas no grau 7 de coloração da casca (frutos completamente amarelos com pontuações marrons/aptos ao consumo), conforme a Tabela 3, não se observou diferença significativa na aparência (Figura 2), descasque e firmeza entre os frutos controle (0 horas) e os tratados com 1-MCP. Quanto à aceitação em relação ao aroma, sabor, aspecto global e IC, notou-se diferença significativa somente entre os frutos controle e aqueles submetidos ao 1-MCP durante 24 horas, sendo os demais tratamentos (6, 9 e 12 horas)

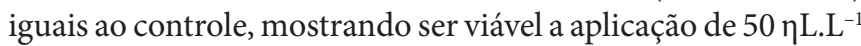

Tabela 2. Médias de aceitação dos consumidores à aparência e intenção de compra de banana Maçã, no grau 4 de coloração da casca (frutos mais amarelos que verdes), submetidas a $50 \eta \mathrm{L} . \mathrm{L}^{-1}$ de $1-\mathrm{MCP}$, em diferentes tempos e armazenadas a $25 \pm 3{ }^{\circ} \mathrm{C}$ e $85 \pm 5 \%$ UR.

\begin{tabular}{|c|c|c|}
\hline \multirow{2}{*}{$\begin{array}{l}\text { Tempo de aplicação } \\
\text { de } 50 \eta L . L^{-1} 1-M C P \\
\text { (horas) }\end{array}$} & \multicolumn{2}{|c|}{ Características avaliadas } \\
\hline & Aparência & Intenção compra \\
\hline 0 (controle) & $6,58^{\mathrm{a}}$ & $3,750^{\mathrm{a}}$ \\
\hline 6 & $6,65^{\mathrm{a}}$ & $3,600^{\mathrm{ab}}$ \\
\hline 9 & $6,55^{\mathrm{ab}}$ & $3,450^{\mathrm{b}}$ \\
\hline 12 & $6,38^{\mathrm{ab}}$ & $3,375^{\mathrm{b}}$ \\
\hline 24 & $5,83^{\mathrm{b}}$ & $3,200^{\mathrm{b}}$ \\
\hline
\end{tabular}

Médias seguidas de letras em comum, na coluna, são iguais entre si pelo Teste de Tukey $(\mathrm{p}>0,05)$. 

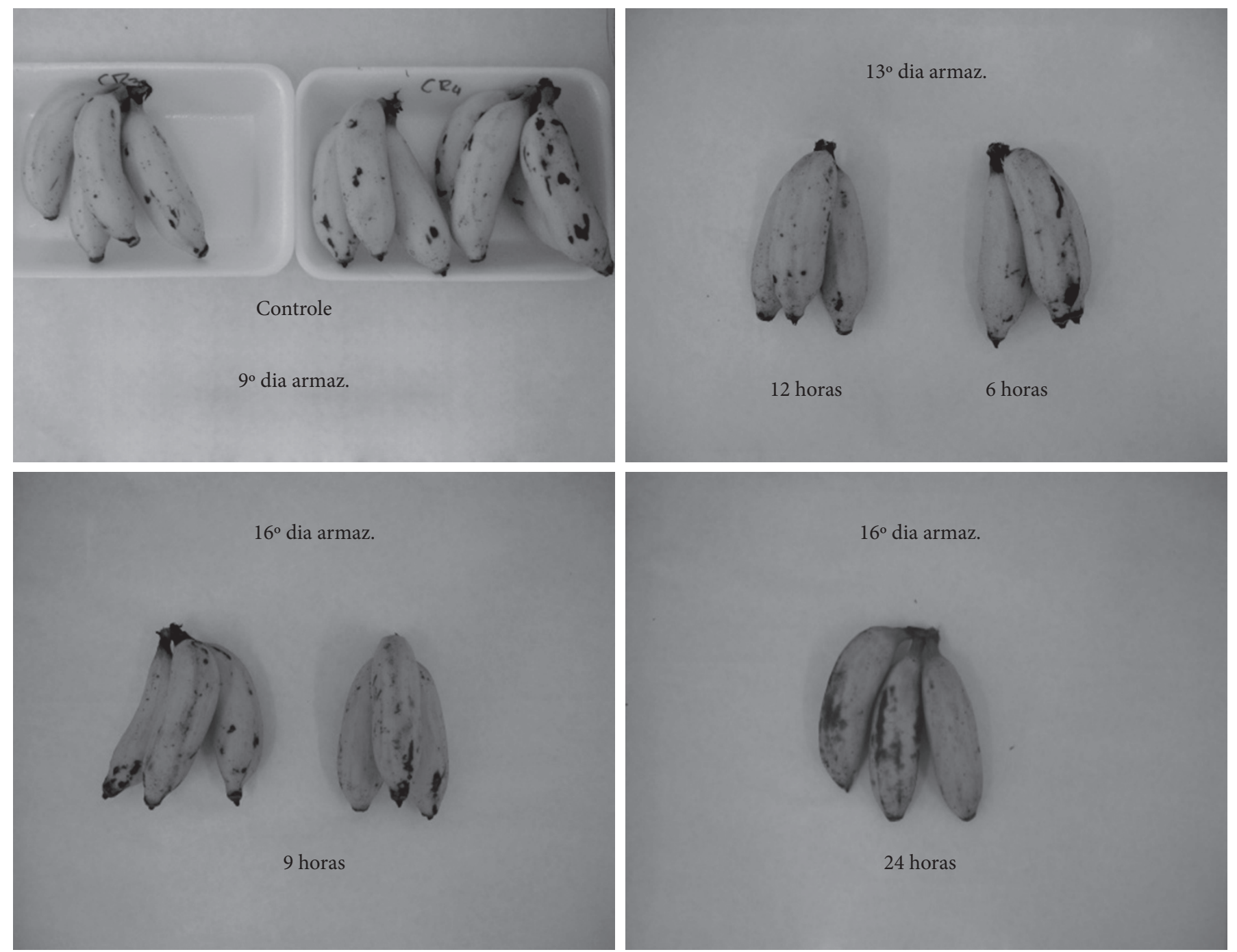

Figura 2. Ilustração da aparência de bananas 'Maçã’ maduras, submetidas a 50 nL.L $\mathrm{L}^{-1}$ de $1-\mathrm{MCP}$, em diferentes tempos e armazenadas a $22 \pm 2{ }^{\circ} \mathrm{C}$ e $80 \pm 5 \%$ UR.

Tabela 3. Médias de aceitação dos consumidores em relação a aparência, descasque, aroma de banana, sabor de banana, firmeza, aspecto global e intenção de compra de banana 'Maçã̃, no grau 7 de coloração da casca (completamente amarelas com pontuações marrons), submetidas a $50 \eta \mathrm{L} . \mathrm{L}^{-1}$ de 1 -MCP, em diferentes tempos e armazenadas a $25 \pm 3{ }^{\circ} \mathrm{C}$ e $85 \pm 5 \% \mathrm{UR}$.

\begin{tabular}{|c|c|c|c|c|c|c|c|}
\hline \multirow{2}{*}{ 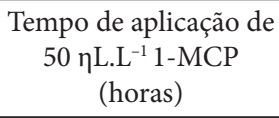 } & \multicolumn{7}{|c|}{ Características avaliadas } \\
\hline & Aparência & Descasque & $\begin{array}{c}\text { Aroma } \\
\text { de banana }\end{array}$ & $\begin{array}{c}\text { Sabor de } \\
\text { banana }\end{array}$ & Firmeza & $\begin{array}{c}\text { Aspecto } \\
\text { global }\end{array}$ & $\begin{array}{l}\text { Intenção } \\
\text { compra }\end{array}$ \\
\hline 0 (controle) & $6,95^{\mathrm{ab}}$ & $7,68^{\mathrm{a}}$ & $7,70^{\mathrm{a}}$ & $7,15^{\mathrm{a}}$ & $7,38^{\mathrm{a}}$ & $7,33^{\mathrm{a}}$ & $4,25^{\mathrm{a}}$ \\
\hline 9 & $7,40^{\mathrm{ab}}$ & $7,50^{\mathrm{a}}$ & $7,65^{\mathrm{ab}}$ & $7,25^{\mathrm{ab}}$ & $7,80^{\mathrm{a}}$ & $7,53^{\mathrm{a}}$ & $4,08^{\mathrm{ab}}$ \\
\hline 12 & $6,78^{\mathrm{b}}$ & $7,30^{\mathrm{a}}$ & $7,50^{\mathrm{ab}}$ & $7,25^{\mathrm{ab}}$ & $7,73^{\mathrm{a}}$ & $7,35^{\mathrm{a}}$ & $3,93^{\mathrm{ab}}$ \\
\hline
\end{tabular}

Médias seguidas de letras em comum, na coluna, são iguais entre si pelo Teste de Tukey (p > 0,05).

de 1-MCP durante 6, 9 e 12 horas para promoção da extensão da vida pós-colheita, mantendo-se a qualidade sensorial dos frutos quando maduros $(\mathrm{p}<0,05)$.

A coloração da casca foi avaliada instrumentalmente nos graus 4 e 7 de coloração da casca e mediu-se o valor $a^{\star}$ (verde a vermelho) e valor $\mathrm{b}^{*}$ (azul a amarelo), conforme as Tabelas $4 \mathrm{e} 5$. Não houve diferença significativa no valor $a^{\star}$ entre os tratamentos nos diferentes graus de coloração da casca avaliados (Tabela 4). Notou-se, a despeito do tempo de aplicação, aumento nos valores $\mathrm{a}^{*} \mathrm{e} \mathrm{b}^{*}$, indicando desverdecimento e concomitante amarelecimento da casca dos frutos (Tabelas 4 e 5). Os resultados de coloração da casca do presente trabalho já haviam sido verificados por Pinheiro et al. (2006) em trabalho com bananas submetidas ao 1-MCP. Os tratamentos 6, 9 e 12 horas 
Tabela 4. Cor da casca (Valor a ${ }^{*}$ de bananas cv. Maçã, submetidas a $50 \eta \mathrm{L} . \mathrm{L}^{-1}$ de 1 -MCP, em diferentes tempos e armazenadas a $25 \pm 3{ }^{\circ} \mathrm{C}$ e $85 \pm 5 \%$ UR

\begin{tabular}{|c|c|c|}
\hline \multirow{2}{*}{ 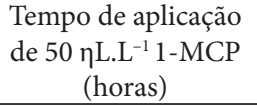 } & \multicolumn{2}{|c|}{ Valor $\mathrm{a}^{*}$} \\
\hline & Grau 4 & Grau 7 \\
\hline 0 (controle) & $-0,69$ & 5,53 \\
\hline 6 & $-2,8$ & 5,84 \\
\hline 9 & $-2,67$ & 6,04 \\
\hline 12 & $-2,45$ & 7,21 \\
\hline 24 & $-1,15$ & 7,29 \\
\hline Médias & $-1,96^{\mathrm{a}}$ & $6,38^{\mathrm{b}}$ \\
\hline
\end{tabular}

Médias seguidas de letras em comum, na linha, são iguais entre si pelo Teste de Tukey $(\mathrm{p}>0,05) .{ }^{*}$ Intensidade de cor de verde/vermelho.

Tabela 5. Cor da casca (Valor $b^{*}$ ) de bananas cv. Maçã, submetidas a $50 \eta \mathrm{L} . \mathrm{L}^{-1}$ de $1-\mathrm{MCP}$ e armazenadas a $25 \pm 3{ }^{\circ} \mathrm{C}$ e $85 \pm 5 \%$ UR.

\begin{tabular}{|c|c|c|c|}
\hline \multirow{2}{*}{ 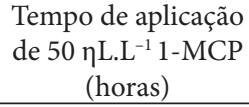 } & \multicolumn{2}{|c|}{ Valor $b^{*}$} & \multirow[t]{2}{*}{ Médias } \\
\hline & Grau 4 & Grau 7 & \\
\hline 0 (controle) & 46,44 & 46,92 & $46,68^{\mathrm{b}}$ \\
\hline 6 & 44,43 & 45,91 & $44,75^{\mathrm{ab}}$ \\
\hline 9 & 44,43 & 47,35 & $45,89^{\mathrm{ab}}$ \\
\hline 12 & 41,0 & 46,66 & $43,83^{\mathrm{ab}}$ \\
\hline 24 & 43,10 & 43,22 & $43,16^{\mathrm{a}}$ \\
\hline Médias & $43,71^{\mathrm{a}}$ & $46,01^{\mathrm{b}}$ & \\
\hline
\end{tabular}

Médias seguidas de letras em comum, na coluna e linha, são iguais entre si pelo Teste de Tukey ( $\mathrm{p}>0,05) .{ }^{*}$ intensidade de cor de azul/amarelo.

apresentaram, em média, valor $b^{\star}$ igual ao controle (Tabela 5). Entretanto, houve diferença significativa no valor $b^{*}$ entre os frutos controle e os tratados com 1-MCP durante 24 horas, os quais apresentaram menor valor $\mathrm{b}^{\star}$ ou seja, menor intensidade de coloração amarela da casca, embora não tenham apresentado coloração mais verde que os frutos controle, pois apresentaram o mesmo valor $\mathrm{a}^{\star}$.

Estes resultados podem justificar a menor aceitabilidade na aparência, aspecto global e IC dos frutos tratados durante 24 horas. Provavelmente este tempo de exposição (24 horas) a $50 \eta \mathrm{L} . \mathrm{L}^{-1}$ de 1 -MCP causou alteração no metabolismo dos frutos, pois apresentaram, além de mudanças na coloração da casca, menor aceitabilidade em relação ao aroma e sabor, embora tenham apresentado mesma aceitabilidade com relação ao descasque e firmeza sensorial.

A avaliação instrumental da firmeza também foi realizada nos graus 4 e 7 de coloração da casca (Tabela 6). Observou-se, a despeito da aplicação de 1-MCP, queda nítida da firmeza com $\mathrm{o}$ amadurecimento dos frutos. Notou-se diferença significativa entre os tratamentos somente no grau 4 de coloração da casca, no qual os frutos tratados com 1-MCP apresentaram menor firmeza que o controle, à exceção do tratamento durante 24 horas. Este fato pode ser justificado também pela ocorrência do amarelecimento desuniforme da casca, que dificultou a determinação exata do grau 4. Os resultados de firmeza medidos instrumentalmente no grau 7 coincidem com a avaliação sensorial da firmeza, na qual os provadores não detectaram diferença entre os tratamentos.
Tabela 6. Firmeza (Newtons) de bananas cv. Maçã, no grau 7 de coloração da casca (completamente amarelas com pontuações marrons), submetidas a $50 \eta L . L^{-1}$ de 1 -MCP, em diferentes tempos e armazenadas a $25 \pm 3{ }^{\circ} \mathrm{C}$ e $85 \pm 5 \%$ UR.

\begin{tabular}{|c|c|c|}
\hline \multirow{2}{*}{ 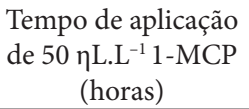 } & \multicolumn{2}{|c|}{ Firmeza $(\mathrm{N})$} \\
\hline & Grau 4 & Grau 7 \\
\hline 0 (controle) & $8,38^{\mathrm{bA}}$ & $3,84^{\mathrm{aB}}$ \\
\hline 6 & $5,78^{\mathrm{aA}}$ & $3,92^{\mathrm{aB}}$ \\
\hline 9 & $5,50^{\mathrm{aA}}$ & $4,03^{\mathrm{aB}}$ \\
\hline 12 & $6,20^{\mathrm{aA}}$ & $4,2^{\mathrm{aB}}$ \\
\hline 24 & $6,91^{\mathrm{abA}}$ & $4,02^{\mathrm{aB}}$ \\
\hline
\end{tabular}

Médias seguidas de letras minúsculas em comum, na coluna, são iguais entre si pelo Teste de Tukey $(\mathrm{p}>0,05)$. Médias seguidas de letras maiúsculas em comum, na linha, são iguais entre si pelo Teste de Tukey $(p>0,05)$.

\section{Conclusões}

A aplicação de 50 nL.L $\mathrm{L}^{-1}$ de 1-metilciclopropeno (MCP) durante 12 horas é a mais adequada, pois promove prolongamento na vida pós-colheita, com base nas primeiras mudanças de coloração da casca de bananas da cv. Maçã, armazenadas a $25 \pm 3{ }^{\circ} \mathrm{C}$ e $85 \pm 5 \%$ UR, em aproximadamente 11 dias, mantendo, nos frutos maduros, a qualidade sensorial, intenção de compra, firmeza e coloração da casca sem diferença significativa $(\mathrm{p}>0,05)$ dos frutos que não foram tratados com o produto, além de promover aceitabilidade, em relação à aparência avaliada no grau 4 de coloração da casca, igual a dos frutos não submetidos ao 1-MCP.

A aplicação durante 9 horas apresenta-se como segunda alternativa mais viável, prolongando a vida pós-colheita da banana-maçã em 8 dias, sem afetar as variáveis citadas acima.

\section{Agradecimentos}

Ao Conselho Nacional de Desenvolvimento Científico e Tecnológico CNPq e à Fundação de Amparo à Pesquisa do Estado de Minas Gerais - FAPEMIG, entidades governamentais promotoras do desenvolvimento científico e tecnológico e ainda a AgroFresh/Rohm and Hass Company.

\section{Referências bibliográficas}

AGRIANUAL. Mercado e perspectiva: banana. São Paulo, 2007. Disponível em: <www.ifnp.org.br>. Acesso em: 10 mar. 2007.

BLANKENSHIP, S. M.; DOLE, J. M. 1-Methylcyclopropene: a review. Postharvest Biology and Technology, v. 28, n. 1, p. 1-25, 2003.

BOTREL, N. et al. Inibição do amadurecimento de banana "PrataAnã” com a aplicação do 1-metilciclopropeno. Revista Brasileira de Fruticultura, v. 24, n. 1, p. 53-56, 2002.

BRASIL. Ministério da Agricultura e do Abastecimento. Balança comercial do agronegócio. Brasília, 2007. Disponível em: <http:॥ www.agricultura.gov.br>. Acesso em: 10 set. 2007a.

BRASIL. Agência Nacional de Vigilância Sanitária. Portaria n. 354, de 11 de agosto de 2006. Aprova e promulga o Regimento Interno da Agência Nacional de Vigilância Sanitária (ANVISA) e dá outras providências. Diario Oficial da União, Poder Executivo, Brasília, DF, 02 de janeiro de 2007. Disponível em: <http://www4.anvisa. 
gov.br/base/visadoc/CP/CP\%5B17161-1-0\%5D.PDF>. Acesso em: 10 mar. 2007b.

EMPRESA DE PESQUISA AGROPECUÁRIA. Genoma Banana. Brasília, 2006. Disponível em: www.cenargen.embrapa.br/cenargen/ pdf/genobanana.pdf. Acesso em: 19 out. 2006.

FERREIRA, D. F. Análises estatísticas por meio do SISVAR para Windows. Versão 4.0. In: REUNIÃO ANUAL BRASILEIRA DA SOCIEDADE INTERNACIONAL DE BIOMETRIA, 45, 2000, São Carlos. Resumos... São Carlos: UFSCar, 2000. p. 235.

GOLDING, J. B. et al. Application of 1-MCP and propylene to identify ethylene-dependent ripening processes in mature banana fruit. Postharvest Biology and Technology, v. 14, n. 1, p. 87-98, 1998.

HARRIS, D. R. et al. Effect of fruit maturity on efficiency of 1-methylcyclopropene to delay the ripening of bananas. Postharvest Biology and Technology, v. 20, n. 3, p. 303- 308, 2000.
JIANG, Y.; JOYCE, C. D.; MACNISH, A. J. Extension of shelf life of banana fruit by 1-methylcyclopropene in combination with polyethylene bags. Postharvest Biology and Technology, v. 16, n. 2, p. 187-193, 1999.

MEILGAARD, M.; CIVILLE, G. V.; CARR, B. T. Sensory evaluation techniques. 3 ed. London: CRC, 1999. 387 p.

PINHEIRO, A. M. P.; VILAS BOAS, E. V. B.; MESQUITA, C. T. Ação do 1-metilciclopropeno (1-MCP) na vida de prateleira da banana 'Maçã.' Revista Brasileira de Fruticultura, v. 27, n. 1, p. 25-28, 2005.

PINHEIRO, A. C. M. et al. Pós-colheita de bananas "Maçâ" submetidas ao 1-metilciclopropeno e armazenadas a temperatura ambiente. Revista Ciência e Agrotecnologia, v. 30, n. 2, p. 323-320, 2006.

WATKINS, C. B. The use of 1-Methylcyclopropene (1-MCP) on fruits and vegetables. Biotechnology Advances, v. 24, n. 4, p. 389-409, 2006. 